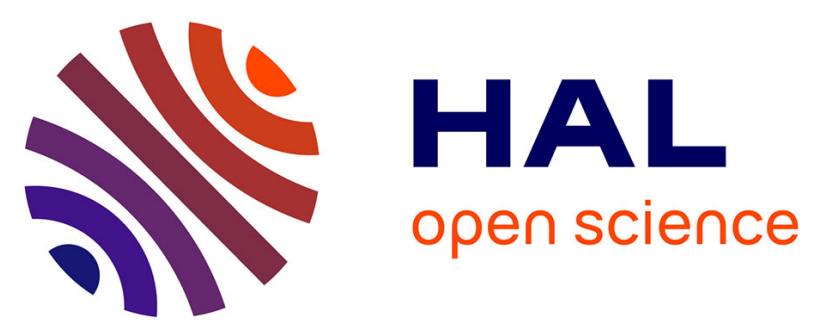

\title{
Probing the Jupiter-Io interaction with synergistic measurements of radio and ultraviolet auroral emissions from Juno, Nançay and HST observatories
}

\author{
Laurent Lamy, Lucas Colomban, Philippe Zarka
}

\section{To cite this version:}

Laurent Lamy, Lucas Colomban, Philippe Zarka. Probing the Jupiter-Io interaction with synergistic measurements of radio and ultraviolet auroral emissions from Juno, Nançay and HST observatories. Europlanet Science Congress 2021, Sep 2021, Virtual Meeting, France. 10.5194/epsc2021-707 . hal03536596

\section{HAL Id: hal-03536596 \\ https://hal.science/hal-03536596}

Submitted on 21 Jan 2022

HAL is a multi-disciplinary open access archive for the deposit and dissemination of scientific research documents, whether they are published or not. The documents may come from teaching and research institutions in France or abroad, or from public or private research centers.
L'archive ouverte pluridisciplinaire $\mathbf{H A L}$, est destinée au dépôt et à la diffusion de documents scientifiques de niveau recherche, publiés ou non, émanant des établissements d'enseignement et de recherche français ou étrangers, des laboratoires publics ou privés. 
EPSC Abstracts

Vol. 15, EPSC2021-707, 2021

https://doi.org/10.5194/epsc2021-707

Europlanet Science Congress 2021

(C) Author(s) 2022. This work is distributed under

the Creative Commons Attribution 4.0 License.

\title{
Probing the Jupiter-Io interaction with synergistic measurements of radio and ultraviolet auroral emissions from Juno, Nançay and HST observatories
}

\author{
Laurent Lamy ${ }^{1,2}$, Lucas Colomban ${ }^{3}$, and Philippe Zarka ${ }^{1}$ \\ ${ }^{1}$ Laboratoire d'Etudes Spatiales et d'Instrumentation en Astrophysique, Observatoire de Paris, PSL, CNRS, Meudon, France \\ (laurent.lamy@obspm.fr) \\ ${ }^{2}$ Laboratoire d'Astrophysique de Marseille, Pythéas, Univ. Aix-Marseille, CNRS, CNES, Marseille, France \\ ${ }^{3}$ Laboratoire de Physique et de Chimie de l'Environnement et de l'Espace, Univ. Orléans, CNRS, Orléans, France
}

The prominent component of Jovian decametric (auroral) emissions is induced by Io. Io decametric emissions (Io-DAM) have thus been monitored on a regular basis by Earth- or Space-based radio observatories for several decades. They display a typical arc-shaped structure in the time-frequency plane which results from the motion of the Io flux tube relative to the observer convolved with the anisotropic radio emission cone. Remote determination of the Io-DAM beaming pattern was used to check the emission conditions at the source (e.g. Queinnec \& Zarka, 1998). It has been done at several occasions using various models of magnetic field/lead angles which introduce significant uncertainties. Nevertheless, Io-DAM arcs were shown to be consistent with oblique emissions triggered by the Cyclotron maser Instability from loss-cone electron distributions of a few keVs (Hess et al., 2008). The CMI validity for Jovian DAM and the prominence of loss cone electron distributions has been later confirmed by Juno in situ measurements (e.g. Louarn et al, 2017). In this study, we took advantage of simultaneous radio/UV or bi-point stereoscopic radio measurements provided by Juno/Waves, the Nançay Decameter Array and the Hubble Space Telescope to unambiguously derive the beaming pattern of several Io-DAM arcs and compare it with theoretical expectations. We then assess the energy of CMI-unstable auroral electrons at the source and discuss our results at the light of similar independent studies reaching different conclusions. 